\title{
Psychiatric Effects of Traumatic Brain Injury
}

\author{
Brig S Sudarsanan (Retd) ${ }^{*}$, Lt Col S Chaudhary (Retd) ${ }^{+}$, Surg Capt AA Pawar ${ }^{\#}$ K Srivastava**
}

\begin{abstract}
In India 30,000 people die and $1,25,000$ become disabled due traumatic brain injury (TBI). The psychiatric sequalae of TBI can be acute and chronic. Chronic sequalae of TBI are usually ignored and may take the form of defects of cognition, memory, perception, language or intelligence. It may also lead to inappropriate aggression, sexual behaviour, personality change, mood changes, neurosis and psychosis. Neuropsychological assessment of TBI can be pharmacological or behavioural. Survivors of TBI are referred to a walking wounded and require to be cared for.
\end{abstract}

MJAFI 2006; $62: 259-263$

Key Words : Traumatic brain injury; Psychiatric sequelae; Cognitive sequelae; Personality change; Post-concussional syndrome

\section{Introduction}

$\mathrm{T}^{\mathrm{s}}$ raumatic Brain Injury (TBI) is a silent epidemic of modern times. In India 30,000 persons die and 125,000 persons are disabled every year due to TBI. The financial loss to the nation is estimated at about Rs.350 crores annually. TBI often occur in the 15-25 year age group. Advances in neuroimaging and improved management has led to an increasing number of survivors with chronic sequelae, leading to an increased demand of rehabilitation services. Multicenteric outcome studies have shown that $35 \%$ of severe head injury patients will die, $1-5 \%$ will remain vegetative and $5-18 \%$ will continue to be severely disabled six months after TBI $[1,2]$.

The major causes of TBI are motor vehicle accidents, falls, assaults, sports accidents, gunshot wound or violent shaking of a young child [3-7] (Table 1). The severity of psychiatric sequelae of TBI is determined by factors existing before, during and after the injury [3,9] (Table 2).

\section{Psychiatric sequelae of TBI}

\section{Acute Psychiatric Sequelae}

Loss of consciousness in TBI may be brief or protracted. On recovery of consciousness, patients develop confusion, agitation, disorientation and delirium. The causes of delirium in TBI patients are given in Table 3. Inadequate sensory and social stimulation, anxiety or disturbed interpersonal relationships play a role in susceptibility to delirium [10].

\section{Chronic Psychiatric sequelae of TBI (Table 4)}

Cognitive deficits: Impairement in efficiency and speed of information processing, attention and vigilance are seen in most cases. Alertness is impaired in severe TBI. The patient may be withdrawn, dull, and apathetic. Deficit of alertness often accompany deficits of motivation. Divided attention deficits are present [11].

Memory: Newly acquired knowledge is forgotten. Selective impairement of memory may persist depending upon the circumscribed damage to structures in

Table 1

Causes of head injury (all figures in percentages)

\begin{tabular}{|c|c|c|c|c|c|}
\hline Causes & $\begin{array}{c}\text { D'Netto \& } \\
\text { Kishore [3] } \\
\quad(n=40)\end{array}$ & $\begin{array}{c}\text { Chatterjee \& } \\
\text { Kishore [4] } \\
(n=37)\end{array}$ & $\begin{array}{l}\text { Sabhesan } \\
\text { et al [5] } \\
(n=134)\end{array}$ & $\begin{array}{l}\text { Bharti } \\
\text { et al [6] } \\
(n=50)\end{array}$ & $\begin{array}{c}\text { Chaudhury } \\
\text { et al [7] } \\
(n=146)\end{array}$ \\
\hline Road traffic accidents & 45 & 40.5 & 53.7 & 49.1 & 58.9 \\
\hline Falls & 25 & 51.4 & 16.4 & 23.6 & 29.5 \\
\hline Blows & 10 & 8.1 & 29.9 & 19.5 & 6.9 \\
\hline Missiles & 20 & - & - & 3.9 & 4.8 \\
\hline Others & - & - & 4 & 3.9 & - \\
\hline
\end{tabular}

*Ex-Consultant (Psychiatry), Base Hospital, Delhi Cantt. ${ }^{+}$Ex-Associate Professor, ${ }^{* *}$ Scientist 'E' (Department of Psychiatry), AFMC, Pune. "Senior Advisor (Psychiatry), INHS Asvini, Colaba, Mumbai. 
diencephalon or medial temporal lobe structures. Both recent and remote memory may be impaired, but immediate memory may be spared [12].

\section{Table 2}

Factors influencing psychiatric sequelae of traumatic brain injury

Localization and severity of injury

Type of injury

Anemia

Endocrine complications

Intellectual functioning

Premorbid personality

Premorbid psychiatric illness (including alcoholism)

Premorbid behavioral problems (children)

Unfavorable global outcome according to the Glasgow Outcome

Scale

A lower score on the Mini-Mental State examination

Increasing age

Arteriosclerosis

Social support

Emotional impact of the injury

Environmental stress including compensation, litigation issues,

Physical and cognitive handicaps

Neurological disorder

Apolipoprotein E status

Table 3

Causes of delirium in patients with traumatic brain injury

Mechanical effects (acceleration or deceleration, contusion and others)

Cerebral edema

Haemorrhage

Infection

Subdural hematoma

Seizure

Hypoxia (cardiopulmonary or local ischemia)

Increased intracranial pressure

Alcohol intoxication or withdrawal, Wernicke's encephalopathy

Reduced hemoperfusion related to multiple traumas

Fat embolism

Change in $\mathrm{pH}$

Metabolic and electrolyte disturbance

Malnutrition with vitamin and mineral deficiency

Anemia

Inadequate pain relief

Medications (barbiturates, steroids, opioids, and anticholinergics)

Table 4

Chronic psychiatric sequelae of head injury (all figures in percentages)

\begin{tabular}{|c|c|c|c|c|c|c|}
\hline Sequelae & $\begin{array}{l}\text { Hilbom }[8] \\
(\mathrm{n}=3552)\end{array}$ & $\begin{array}{c}\text { Ota [9] } \\
(\mathrm{n}=1168)\end{array}$ & $\begin{array}{l}\text { Chatterjee \& Kishore [4] } \\
\qquad(\mathrm{n}=37)\end{array}$ & $\begin{array}{l}\text { Keshvan et al }[20] \\
\qquad(\mathrm{n}=60)\end{array}$ & $\begin{array}{l}\text { Sabhesan et al [5] } \\
\qquad(n=134)\end{array}$ & $\begin{array}{l}\text { Chaudhury et al [7] } \\
\qquad(\mathrm{n}=146)\end{array}$ \\
\hline Cognitive & 2 & 3 & 16.2 & 3 & 2.2 & 3.4 \\
\hline Personality & 18 & 6 & 8 & - & 7.5 & 4.8 \\
\hline Psychoses & 8 & 5 & 18.9 & 1 & 14.9 & 8.9 \\
\hline Neuroses \& others & 11 & 22 & - & 47 & 12.7 & 20.5 \\
\hline Total & 39 & 36 & 43.2 & 51 & $29.1^{*}$ & 37.7 \\
\hline
\end{tabular}

*Total is less as some patients developed symptoms sequentially
Perception: Visual dysfunction affects about 50\% of TBI patients. Visuo-perceptual disturbances such as impaired figure-ground perception and constructional abilities may be present in severe TBI as part of a general cognitive decline. Focal visuo-perceptual and visuoconstructive disabilities are rare [13].

Language: Anomia and word finding difficulties are present after TBI. Expressive aphasias are more common than receptive aphasias. TBI patients with aphasias have more severe cognitive deficit compared to those patients without aphasia. Recovery from aphasia and related language disorder is greater than recovery from memory and other cognitive deficits when patients were tested after one year [14].

Intelligence: Both performance and verbal IQ are reduced in acute and chronic phases of severe TBI. Recovery of verbal IQ is faster. Performance IQ continued to be lower even after three years. $10 \%$ of TBI patients with prolonged coma develop some degree of hydrocephalus, which may present as progressive intellectual deterioration.

Factors predisposing to the development of posttraumatic dementia include severity of head injury, multiplicity of head trauma, age greater than 60 years, alchoholism and atherosclerosis. The 'punch drunk' syndrome may be seen in boxers 5-40 years after retirement [15].

Personality change: Personality change may result from neurochemical changes or from psychological reaction to TBI. Common changes include excessive tiredness, indifference, concentration and attention disorders, inflexibility, perseveration, inability to anticipate, behavioural disinhibition, irritability, change in quality of relationship with shallowness and obsessive-compulsive symptoms.

Orbitofrontal (pseudopsychopathic) syndrome manifests with disinhibition, antisocial behaviour, affective lability, hyperactivity, sexual preoccupation without overt sexual aggression, impulsivity, distractibility and poor insight. Frontal convexity (pseudodepressed) syndrome presents with apathy, indifference, decreased 
initiative, psychomotor retardation, inflexibility, impersistence and perseveration. Medial frontal syndrome is characterised by akinesia, sparse verbal output and incontinence. Clinically a mixture of these syndromes is common. Severity of behavioral sequelae is more with abnormal EEG or early CT scans indicating significant brain edema. Behavioral sequelae correlate with severity of injury, though such relationship is not linear [16-18].

Aggression: Physical/verbal aggression and impulsiveness are particularly difficult for family members to manage. Sometimes it merely represents an exaggeration of previous personality. This can be managed with anticonvulsants, antidepressants, lithium, calcium channel blockers, beta-blockers, antipsychotics, benzodiazepines and psychostimulants [19].

Sexuality: Limbic structures particularly amygdala, septal nuclei and hypothalamus which form the neuroanatomic and physiologic substrate of human sexual behaviour may be damaged in TBI, resulting in impaired sexuality. Frontal lobe injuries with resultant disinhibition, lack of social judgement, difficulty in modulating and initiating sexual overtures can profoundly affect sexual response.

Alchohol abuse: Many TBI patients are intoxicated at the time of injury. Presence of high alchohol levels in blood not only has a negative impact on length of unconsciousness and behavioural changes and neurocognitive changes but can also affect mortality. Alchohol abuse in the previously head injured can result in pathological intoxication.

Post Concussional Syndrome (PCS) : PCS (Table 5) often follows mild TBI. PCS was the commonest neuropsychiatric sequelae after TBI in a prospective Indian study with an incidence of $43 \%$ [20]. Onset of PCS is usually during the first month after TBI, and

\section{Table 5}

Common symptoms of the post concussion syndrome

1. Somatic symptoms

Headache

Dizziness

Fatigue

2. Cognitive symptoms

Memory difficulties

Impaired concentration

3. Perceptual symptoms

Tinnitus

Sensitivity to noise

Sensitivity to light

4. Emotional symptoms

Depression

Anxiety

Irritability may slightly reduce after 3-6 months, though a significant percentage continue to be symptomatic. PCS patients have reduced blood flow through the brain as well as prolongation of mean cerebral circulation time. Abnormal audiologic examination has been reported in PCS patients complaining of dizziness, hearing disturbance and tinnitus. PET has demonstrated changes in cerebral glucose metabolism greater than would be expected by the lesions detected by CT and MRI scans. SPECT studies have shown focal abnormal regional cerebral blood flow.

Mood disorders: Following TBI, depression is more common than mania. Depression occurs more frequently with lesions of frontal and temporal lobes and left anterior lesions. The recovering patient must come to terms with physical and mental limitations, and may psychologically mourn those functions impaired or lost. The common symptoms of depression may be less pronounced in TBI patients due to overall personality flattening. Erratic or poor recovery, or worsening of a neurological deficit after initial recovery, may be signs of depression. Suicide potential should always be evaluated [21]. Mania occurs most often with lesions located in limbic or limbic related structures and rightsided lesions. Almost $50 \%$ of post-traumatic maniac patients have abnormal EEG. Suicide is considerably increased after TBI and accounted for $14 \%$ of all deaths in an 18-year follow up of those with war brain injuries. An association with lesions in frontal and temporal lobes has been reported [22].

Psychoses: Paranoid psychoses can occur independently or as part of post-traumatic dementia. Epileptic psychosis and reactive psychoses are reported. Simple hallucinosis is very rare.

Neuroses: Neuroses are among the commonest psychiatric sequelae of TBI. Anxiety may coexist with depression or present alone. Phobias, obsessivecompulsive disorders and post traumatic stress disorder may emerge. Dissociative (Conversion) symptoms including fits, fugue, amnesia, Ganser states, paralysis, anaesthesia and disturbance of speech, sight or hearing are not uncommon. A neurasthenic reaction may incapacitate the patient for months or even years.

\section{Neuropsychological assessment of TBI patients}

Neuropsychological assessment can help in diagnosis, treatment, follow-up and rehabilitation of TBI patients [23]. Commonly used neuropsychological techniques are given in Table 6. Intensive neuropsychological examinations should not be undertaken in the acute and post-acute stages as findings become quickly outdated and these patients are often not capable of meaningful cooperation [24].

Unless direct damage to the left hemisphere has been 
Table 6

Commonly used techniques for neuropsychological assessment in TBI

1. For assessing severity:

Glasgow coma scale

Rancho scale : Levels of cognitive functioning

Galveston - orientation and amnesia test

2. For assessing outcome:

Glasgow outcome scale

3. For assessing cognitive functions:

Mini mental status examination

Tests of abstract problem solving ability

4. For assessing personal adjustment:

Rorschach test

5. Assessment of psychosocial consequences:

Portland adaptability inventory

Katz adjustment scale

sustained, most head trauma patients have little or no difficulty with verbal tests, except problems with verbal retrieval and sometimes, fluency. They may do well on tests mediated by the posterior areas of the cortex, which include tests of constructional abilities and perceptual accuracy that are uncomplicated by memory, organization or speed requirement. Memory problems tend to be exacerbated by patients difficulty in identifying what may be relevant among a number of information bits so that their recall is reduced not only by quantity but also by its usefulness [25]. Unless examination of brain is geared to elicit impairement common to head trauma victims, these often seriously handicapping deficits may not become evident [26]. Many patients can perform adequately on a conventional psychological examination or prepackaged neuropsychological test batteries.

\section{Management of psychiatric sequelae during early phase of recovery}

Underlying treatable condition should be managed promptly. Unnecessary and high psychotropic medication is avoided. High potency neuroleptics like haloperidol in low doses are useful for acute agitation and delirium. Antidepressants are helpful for sleep disturbances. Benzodiazepines and anticholinergics should be avoided as they may confound the clinical presentation or worsen the patient's confusion and delirium. Exposing the patient to optimum daytime stimulation from visitors, activities, radio and television may help with night time insomnia. For disoriented patients frequent verbal reorientation as well as familiar objects, clocks or calendars may help.

\section{Post-acute and long term management}

TBI patients are very sensitive to medications; hence, treatment should be initiated at low doses with gradual increase. For persistent dysphoria, antidepressants are indicated. ECT is effective in the absence of increased intracranial tension, but possibility of worsening of memory disturbance should be considered. Mania is treated with antipsychotics and mood stabilizers in low doses. In schizophrenia antipsychotic should be used in the lowest effective dosages as they may impair cognitive retraining and may also lower seizure threshold. Treatment of headache may include ergot alkoloids, NSAIDs, beta blockers and antidepressants [21, 27]. Psychostimulants (methyl-phenidate $5 \mathrm{mg}$ bid and dextroamphetamine $2.5 \mathrm{mg}$ bid are useful in the treatment of inattention, distractibility, disorganization, hyperactivity, impulsivity, hypoarousal, apathy, hypersomnia, mood and cognition. Dopaminergic agents (amantadine, bromocriptine and levodopa) have been used as cognitive enhancers [28]. Naltrexone in doses of $50 \mathrm{mg}-100 \mathrm{mg} /$ day is useful in treating self-injurious behaviour. Buspirone, a partial 5 HT-1A agonist is useful in the treatment of anxiety disorders and aggression in doses of $45 \mathrm{mg}-60 \mathrm{mg} /$ day. Beta-blockers, such as propranolol have also been used to treat aggression and violent behavior.

Rehabilitation includes cognitive rehabilitation, behavioural treatment, social skills training, vocational training, individual therapy, group therapy and family therapy. Rehabilitation should begin on the day of the injury and continue until the patient is stable or has reached his or her pre-injury baseline. Value of early mobilization is well recognized. Change of employment may be warranted if the job prior to head injury was intellectually demanding. Functional skill development is the hallmark of cognitive retaining programs. Patients disability is analysed in the context in which he has to work. The therapist helps the patient to structure the tasks. A computer based cognitive retraining program has been developed at NIMHANS and is available with Department of Psychiatry, AFMC. It aims to improve the information processing capacity using visual stimuli. Behavioral techniques like social skills training may help in reducing disruptive behavior. Operant conditioning by rewarding self-helping behaviour while belligerent and manipulative behaviour are ignored has proved its utility. Relaxation training is useful in anxiety disorders. As the chronicity of the patients disability becomes apparent extended family members who had been helpful often withdraw their support. Families need reassurance that anger, frustration and sorrow are natural emotional reaction for caregivers of head injured patients. Organizing self-help groups, educating the family in handling the patient, providing trained helpers, and much needed respite for temporary periods during holidays and supportive psychotherapy will help in rehabilitation.

\section{Outcome of TBI}

About $10 \%$ will have severe residual disabilities. A 
study of 120 patients between the ages of 18-64 years, interviewed one year after head injury, revealed that $21.7 \%$ had a psychiatric illness, compared with $16.4 \%$ of the general population. Depressive illness was present in $13.9 \%$ of the brain injury patients compared to $0.8 \%$ of the general population, and panic disorder was present in $9.0 \%$ compared to $0.8 \%$ of the general population [29]. Of the 60 patients assessed on average 30 years after head injury, $48.3 \%$ had an axis I disorder that began after head injury, $61.7 \%$ had an axis I disorder during their lifetime and $23.3 \%$ had at least one personality disorder. The most common psychiatric disorders after TBI were major depression $(26.7 \%)$, alcohol abuse or dependence $(11.7 \%)$, panic disorder $(8.3 \%)$, specific phobia $(8.3 \%)$, and psychotic disorders $(6.7 \%)$. The results suggest that TBI may cause lasting vulnerability to psychiatric illness, particularly depressive episodes, delusional disorder, and personality disturbances [30].

\section{Conclusion}

Patients with traumatic brain injury are often referred to as "the walking wounded," because a number of them have persistent psychiatric sequelae. Even though they appear physically "normal", they are disabled socially, occupationally and in personality. Ideally, treatment of these patients should involve a multidisciplinary approach, with the psychiatrist working in close collaboration with the patient, family, neurologist/neurosurgeon, psychologist and social worker.

\section{Conflicts of Interest}

None identified

\section{References}

1. Leishman WA. Organic Psychiatry, $3^{\text {rd }}$ ed. Oxford: Blackwell Science Ltd, 1998; 161-217.

2. Sankla SK, Mishra M, Ansman JI. Think First. Neuorotrauma '98. Proceedings of Neurotrauma Conference, Indore, 1998; $1-5$.

3. D'Netto TB, Kishore R. Psychological aspects of head injury. Medical Journal Armed Forces India 1975; 31: 58-70.

4. Chatterjee SB, Kishore R. Psychiatric disability in brain trauma. Indian Journal of Psychiatry 1979; 21: 279-82.

5. Sabhesan S, Ramaswamy P. Natarajan M. Early behavioural sequelae after head injury. Neurology India 1990; 38: 169-75.

6. Bharti P, Nagar AM, Tyagi U. Pattern of trauma in western Uttar Pradesh. Neurology India 1993; 41: 49-50.

7. Chaudhury S, Bhatoe HS, John TR. Psychological Sequelae of Head Injury. Paper presented at National Conference on Research in Clinical Psychology, AIIMS, New Delhi, 1999.

8. Hilbom E. After effects of brain injuries. Acta Psychtr Scand 1960, 142: 1-195.

9. Ota Y. Psychiatric studies on civilian head injuries. In: Walker AE, Caveness WF, Chrithely M, editors. The late effects of head injury. Illnois: Thomas, 1969.

10. O'Shanick JG. Neuropsychiatric complications in head injury.
Adv Psychosom Med 1986; 16: 173-93.

11. Mishra S, Rao SL. Divided attention in head injury. NIMHANS journal 1994; 12: 157-62.

12. Menon P, Rao SL. Memory storage and encoding in patients with memory deficits after closed head injury. NIMHANS journal 1997; 15: 83-92.

13. Jones RD, Anderson SW, Cole I, Hathaway-Nepple J. Neuropsychological sequelae of traumatic brain injury. In: Rizzo M, Tranel D , editors. Head injury and post-concussive syndrome. New York: Churchill Livingstone, 1996: 395-414.

14. Levin HS, Gary HE, Eisenberg HM, et al. Neurobehavioral outcome one year after severe head injury. Experience of the Traumatic Coma Data Bank. J Neurosurg 1990; 73: 699-709.

15. McCunny RJ, Russo PK. Brain injuries in boxers. Physician and Sports Med 1984; 12: 53-67.

16. Cummings JL. Clinical Neuropsychiatry. New York: Grune and Stratton, 1985, 29-43.

17. Drummond LM, Gravestock S. Delayed emergence of obsessivecompulsive neurosis following head injury. British Journal of Psychiatry 1988; 153: 839-42.

18. Brooks N, Campsie L, Symington C, Beattie A, Mckinley W. The five year outcome of severe blunt head injury: A relatives view. J Neurol Neurosurg Psychiat 1986; 49: 764-70.

19. Davis DL, Boster L. Multifaceted therapeutic inervention with the violent psychiatric patient. Hospital and Community Psychiatry, 1988; 39: 867-9.

20. Keshvan MS, Channbasavanna SM, Reddy GNN. Posttraumatic psychiatric disturbances: patterns and predictors of outcome. Br J Psychiat 1981; 138: 152-60.

21. Rapoport MJ, McCullagh S, Streiner D, Feinstein A. The clinical significance of major depression following mild traumatic brain injury. Psychosomatics 2003; 44: 31-7.

22. Rerkum RV, Bolago I, Finlayson MAI, Lerner S, Link PS. Psychiatric disorders after traumatic brain injury. Brain Injury 1996; 10: 319-27.

23. Lezak MD. Neuropsychological assessment. $3^{\text {rd }}$ ed. New York: Oxford University Press, 1995: 171-93.

24. Stuss DT, Buckle L. Traumatic brain injury: neuropsychological deficits and evaluation at different stages of recovery and in different pathologic subtypes. Journal of head trauma rehabilitation 1992; 7: 40-9.

25. Vakil E, Arbel N, Gozlan M. Relative importance of informational units and their role in long term recall by closed head injured patients and control groups. Journal of Consulting and Clinical Psychology 1992; 7 : 40-9.

26. Walsh KW. Neuropsychology. $2^{\text {nd }}$ ed. Edinburgh: Chruchill Livingstone, 1987: 73-119.

27. Slagel DA. Psychiatric disorder following closed injury. Int'1 J Psy Med 1990; 20: 1-35.

28. Rao V, Lykestos C. Neuropsychiatric Sequelae of traumatic brain injury. Psychosomatics 2000, 41; 2: 95-103.

29. Deb S, Lyons I, Koutzoukis C, Ali I, McCarthy G. Rate of psychiatric illness one year after traumatic brain injury. Am J Psychiatry 1999; 156: 374-8.

30. Koponer S, Taiminen T, Porter R, et al. Axis I and Axis II psychiatric disorders after traumatic brain injury. Am J Psychiatry 2002; 159: 1315-21. 